18

\title{
Оптические свойства и фоторазогрев водных суспензий нанокомпозитных частиц на основе кремния с осажденным золотом
}

\author{
() А.В. Корнилова ${ }^{1,2}$, С.Б. Икрамова ${ }^{3}$, Д.У. Мусаева ${ }^{4}$, А.В. Сюй ${ }^{5}$, В.Ю. Тимошенко \\ ${ }^{1}$ Московский государственный университет имени М.В. Ломоносова, физический факультет, \\ 119991 Москва, Россия \\ ${ }^{2}$ Физический институт им. П.Н. Лебедева РАН, \\ 119991 Москва, Россия \\ ${ }^{3}$ Казахский национальный университет имени аль-Фараби, \\ 050040 Алматы, Казахстан \\ ${ }^{4}$ Национальный исследовательский ядерный университет „МИФИ“, \\ 115409 Москва, Россия \\ ${ }^{5}$ Московский физико-технический институт, центр фотоники и двумерных материалов, \\ 141700 Долгопрудный, Россия \\ e-mail: shargenga@mail.ru
}

Поступила в редакцию 20.12.2021 г.

В окончательной редакции 20.12.2021 г.

Принята к публикации 30.12.2021 г.

Исследованы оптические свойства нанокомпозитных частиц, состоящих из кремниевых ядер с размерами порядка $100 \mathrm{~nm}$ с осажденными на их поверхности золотыми наночастицами меньших размеров. Наблюдается рост поглощения света в ближней инфракрасной области спектра для полученных наночастиц по сравнению с таковым для наночастиц чистого кремния или золота. Эксперименты по измерению температуры водных суспензий показали значительно более высокие скорости фоторазогрева нанокомпозитных частиц при облучении лазерным излучением с длиной волны $810 \mathrm{~nm}$ по сравнению со случаем наночастиц чистого кремния. Расчеты распределения электрического поля показали многократный рост его напряженности вблизи нанокомпозитных частиц при облучении светом в видимом и ближнем инфракрасном диапазонах, а также позволили найти вклады рассеяния и поглощения в спектры экстинкции суспензий наночастиц. Наблюдаемый усиленный фоторазогрев нанокомпозитных частиц может быть использован для применения в антибактериальной обработке и гипертермии рака.

Ключевые слова: нанофотоника, плазмоника, наночастицы, фотогипертермия, кремний, золото.

DOI: $10.21883 /$ OS.2022.04.52275.62-21

\section{Введение}

В настоящее время хорошо исследованы оптические свойства изолированных полупроводниковых и металлических наночастиц (НЧ), проявляющих соответственно квантовый размерный эффект для носителей заряда и локализованный плазмонный резонанс $[1,2]$. Так, известно, что НЧ золота имеют локализованный плазмонный резонанс в спектрах поглощения и рассеяния света, положение и форма которого зависят от формы НЧ и показателя преломления окружающей их среды. В то же время для широко используемых коллоидных растворов золотых НЧ такой резонанс обычно соответствует зеленой области спектра, что не всегда удобно для биофотонных применений ввиду сильного рассеяния и поглощения света данного диапазона. Для смещения пика плазмонного резонанса в инфракрасную (ИК) область можно использовать НЧ сложной формы или их агрегаты, что, однако, технически сложно и зачастую сопровождается увеличением нежелательной нагрузки на биосистему. Другой метод смещения резонанса осаждение НЧ на подложки или другие НЧ с большим показателем преломления [3]. В качестве последних можно использовать НЧ кремния.

Возможным биофотонным применением нанокомпозитных частиц может быть использование их как эффективных поглотителей световой энергии в биомедицинском методе фотогипертермии, заключающемся в увеличении температуры биообъекта выше $41-42^{\circ} \mathrm{C}$ на определенный промежуток времени [4]. Недавно нами было установлено, что с помощью НЧ золота, иммобилизованных на поверхность галлуазитных нанотрубок, возможен локальный фоторазогрев на длине волны локализованного плазмонного резонанса, что позволяет реализовать контролируемое уничтожение нежелательных клеток [5].

Представляет интерес исследовать иммобилизованные плазмонные НЧ на поверхности компактного носителя, например полупроводниковой НЧ кремния, а также изучить возможность дополнительного усиления локальных электрических полей и эффективности поглощения света в области связанных плазмонных и диэлектрических резонансов в нанокомпозитных частицах кремний/золото. Для решения данной задачи на поверх- 
ность сферических кремниевых НЧ были осаждены НЧ золота и исследованы оптические и фототермические свойства водного раствора полученного нанокомпозита.

\section{Методика эксперимента}

Использовались кремниевые (Si) НЧ, полученные радиочастотным разложением силана (ACS Materials, США) со средним диаметром порядка $100 \mathrm{~nm}$. Ocаждение золотых (Au) НЧ проводилось по методике из работы [6] путем выдержки кремниевых НЧ в водном растворе $\mathrm{HAuCl}_{4}(0.4 \mathrm{mM}) / \mathrm{HF}(5 \mathrm{M})$ в течение $10 \mathrm{~s}$, что давало средний размер НЧ Аu около $20 \mathrm{~nm}$. Полученный нанокомпозит промывали несколько раз деионизированной водой и обрабатывали ультразвуком в течение $5 \mathrm{~min}$, затем центрифугировали в течение $10 \mathrm{~min}$ при центробежном ускорении $10^{4} \mathrm{~g}$.

Концентрации элементов ( $\mathrm{Si}$ и $\mathrm{Au}$ ) в полученных образцах нанокомпозитных частиц на основе кремния с осажденными НЧ золота (далее - НЧ $\mathrm{Si} / \mathrm{Au}$ ) определялась методом рентгено-флуоресцентного анализа (РФА) на рентгеновском дифрактометре ДР-02 „Радиан“ для высушенных на воздухе суспензий $\mathrm{HЧ} \mathrm{Si/Au.} \mathrm{Размеры}$ исходных НЧ $\mathrm{Si}$ измерялись с использованием просвечивающего электронного микроскопа (ПЭМ) JEOL JEM-2100. Морфология и химический состав полученных нанокомпозитных частиц, осажденных из раствора на оптически полированные пластины германия, исследовались на сканирующем электронном микросокопе (СЭМ) Tescan Vega с приставкой энергодисперсионного анализа (ЭДА) Oxford Instruments. Для сравнения также исследовались коллоидные растворы $\mathrm{Au} \mathrm{HЧ,}$ полученные методом лазерной абляции твердотельных мишеней из золота чистотой 99.9\% [7]. Спектры экстинкции водных суспензий $\mathrm{HЧ} \mathrm{Si} / \mathrm{Au}$ и чистых $\mathrm{Si}$ и $\mathrm{Au}$ измерялись на спектрофотометре UV-Vis 752P в диапазоне $300-1000 \mathrm{~nm}$ со спектральным разрешением $0.5 \mathrm{~nm}$.

Нагрев водных суспензий исследуемых НЧ под действием лазерного излучения исследовался с помощью тепловизионной камеры Flir $\mathrm{C} 3$, имеющей точность $0.01^{\circ} \mathrm{C}$ и частоту измерений $15 \mathrm{~Hz}$ в диапазоне температур от +5 до $+50^{\circ} \mathrm{C}$. Водные растворы кремниевых НЧ и нанокомпозитных частиц на основе кремния с золотом помещали в пластиковые кюветы объемом по $0.3 \mathrm{ml}$. Концентрации растворов составляли $1.8 \mathrm{~g} / 1$, начальная температура - $20^{\circ} \mathrm{C}$. При облучении использовались непрерывные полупроводниковые лазеры с длинами волн 532, 667 и $800 \mathrm{~nm}$ и мощностью порядка $200 \mathrm{~mW}$ при диаметрах пучка $2 \mathrm{~mm}$.

\section{Моделирование оптических свойств}

Расчеты оптических свойств и пространственного распределения локальных электрических полей проводилось для НЧ, состоящей из кремниевого ядра диамет- ром 100-150 nm с осажденными на его поверхности золотыми НЧ диаметрами $10-20 \mathrm{~nm}$, с использованием программного обеспечения Lumerical Finite Difference IDE (ANSYS, Inc.). Дисперсионные зависимости для показателей преломления воды и кремния были взяты из базы данных Palik, показатели золота - из базы данных CRC для диапазона длин волн от 300 до $1000 \mathrm{~nm}$. Предполагалось, что золотые НЧ случайным образом распределены по внешней поверхности кремниевой НЧ. Задавался источник рассеянного света с амплитудой $1 \mathrm{~V} / \mathrm{m}$ и длительностью импульса $10 \mathrm{fs}$. Расчеты сечений рассеяния и поглощения производились, используя численные решения уравнения Максвелла для заданных граничных условий, методом сложения усредненных векторов Пойнтинга и нормировки на интенсивность источника. Также рассчитывалось пространственное распределение модуля напряженности электрического поля, нормированного на поле источника, при облучении светом с длинами волн, соответствующими длинам волн лазеров, использованных в эксперименте.

\section{Результаты и обсуждения}

Рисунок $1, a$ демонстрирует ПЭМ-изображение исходных НЧ Si. Из анализа ПЭМ-изображений был определен средний диаметр НЧ, который составил $125 \pm 25 \mathrm{~nm}$. На рис. 1, $b$ показаны СЭМ-изображения полученных нанокомпозитных частиц, на которых видны как отдельные НЧ с размерами порядка $100 \mathrm{~nm}$, так и их агрегаты больших размеров. Исследование элементного состава НЧ методом ЭДА (рис. 1,c) позволило оценить их химический состав, который включал 50.2 at.\% кремния, 49.4 at.\% кислорода и 0.4 at.\% золота. Близкие к указанным значениям процентные доли кремния и золота были также определены методом РФА для высушенных на воздухе макроскопических количеств суспензий НЧ.

Опираясь на данные ПЭМ и СЕМ, была построена модель исследуемой композитной НЧ, представляющей собой сферическое ядро диаметром $125 \mathrm{~nm}$ из кристаллического $\mathrm{Si}$ и массива случайно распределенных по его поверхности НЧ Аu диаметром $20 \mathrm{~nm}$ с поверхностной плотностью порядка $200 \mu \mathrm{m}^{-2}$ (рис. $\left.2, a\right)$. На рис. $2, b-d$ показаны рассчитанные распределения модуля напряженности электрического поля в сечении нанокомпозитной частицы. Значения напряженности нормировались на величину поля источника. Рассматриваются картины электрического поля, образующиеся при воздействии на НЧ света с длинами волн, равными используемым в эксперименте. При облучении НЧ $\mathrm{Si} / \mathrm{Au}$ светом с длиной волны $532 \mathrm{~nm}$ напряженность электрического поля между золотыми НЧ увеличивалась в 7 раз по сравнению с исходной (рис. 2, $b$ ), при $667 \mathrm{~nm}-$ в 153 раза (рис. 2,c), при $810 \mathrm{~nm}$ - в 12 раз (рис. 2,d). Полученные результаты можно объяснить тем, что длина волны $667 \mathrm{~nm}$ находится в области усиленного поглощения света, связанного с комбинацией эффектов 

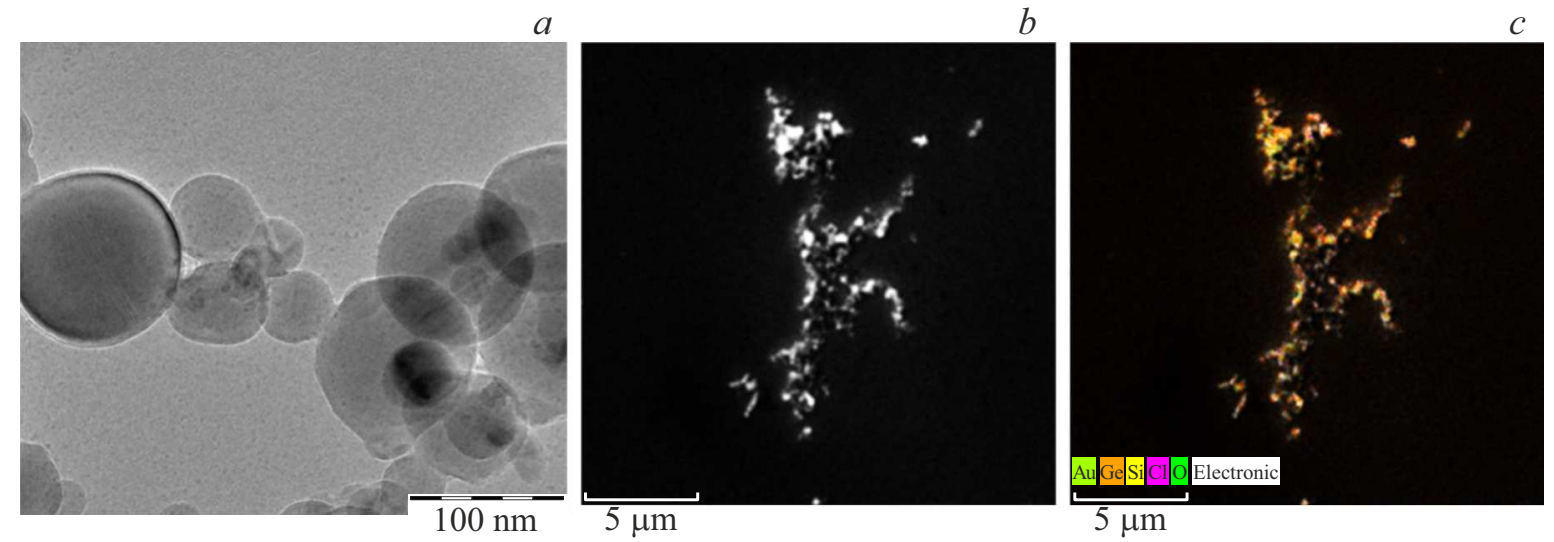

Рис. 1. (a) ПЭМ-изображение исходных НЧ $\mathrm{Si} ;(b)$ СЭМ изображение композитных $\mathrm{HЧ} \mathrm{Si} / \mathrm{Au}$ и $(c)$ соответствующая карта распределения элементов, полученная методом ЭДА.
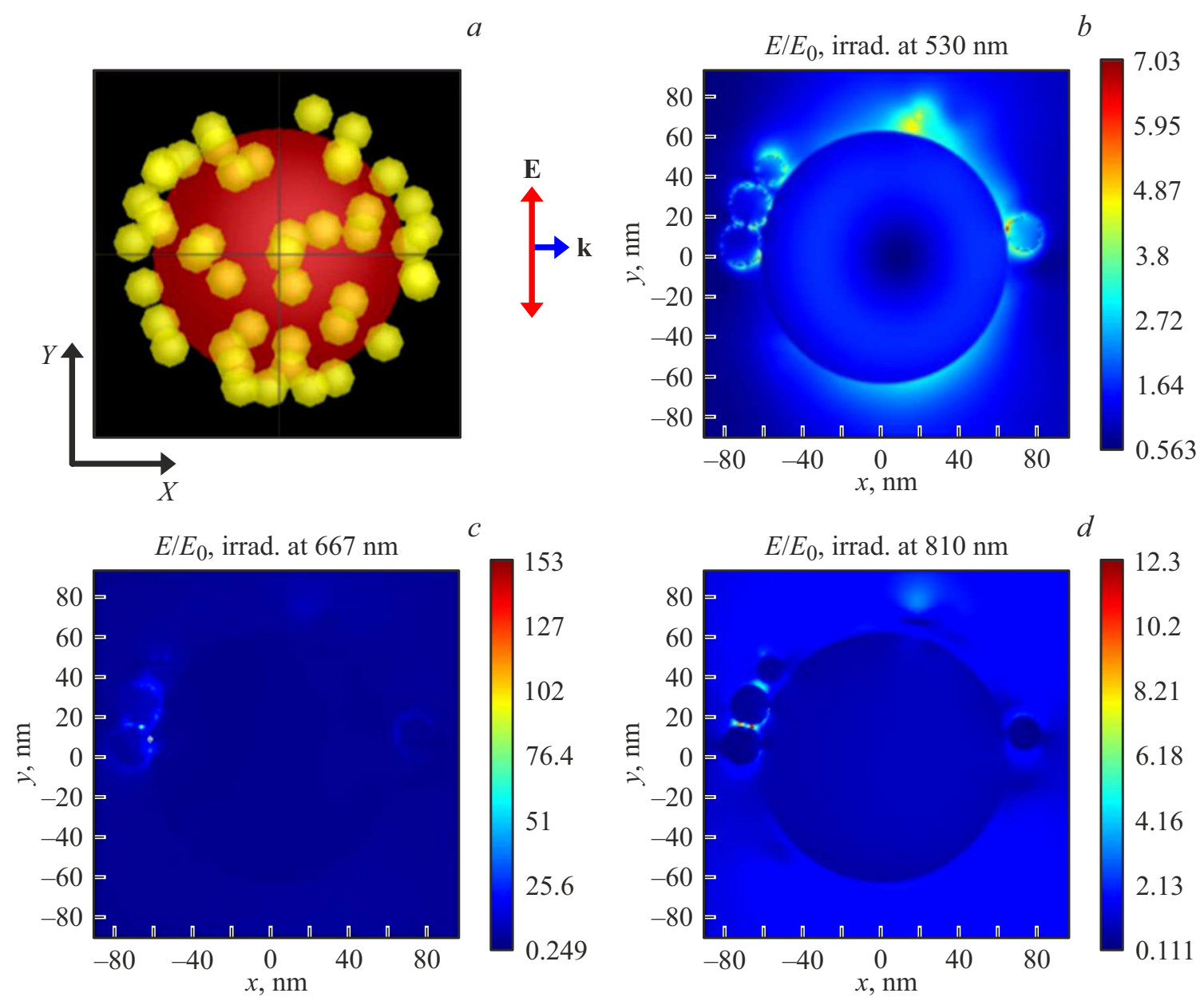

Рис. 2. (a) Модель кремниевой НЧ диаметром $125 \mathrm{~nm}$ со случайно осажденными НЧ золота $20 \mathrm{~nm}$ и $(b, c, d)$ поперечные сечения распределений напряженности электрического поля, нормированной на исходное значение, при освещении светом с длинами волн $530(b), 667(c)$ и $810 \mathrm{~nm}(d)$. Направления электрического поля и волнового вектора показаны синими и красными стрелками.

локализованного плазмонного резонанса в $\mathrm{HЧ} \mathrm{Au}$ и резонанса Ми в $\mathrm{HЧ} \mathrm{Si} \mathrm{[1].}$

Рисунок 3 демонстрирует результаты расчетов сечений поглощения (рис. $3, a$ ) и рассеяния (рис. $3, b$ ) нанокомпозитной частицы $\mathrm{Si} / \mathrm{Au}$ в воде, а также $\mathrm{HЧ}$ $\mathrm{Si}$ и ансамбля НЧ $\mathrm{Au}$ с теми же параметрами и пространственным расположением. Сложная структура резонансов в спектре последних связана с взаимным 

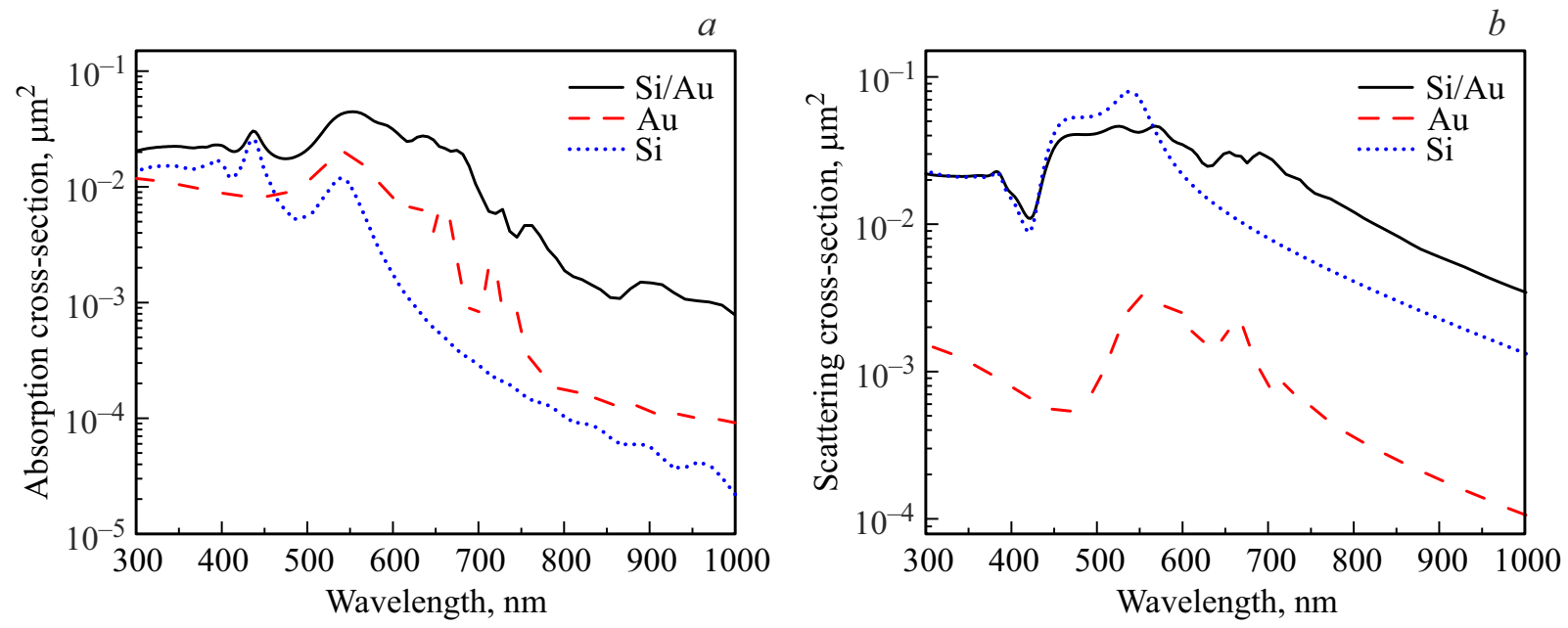

Рис. 3. Расчетные спектры $(a)$ сечений поглощения и $(b)$ рассеяния для нанокомпозитной частицы, состоящей из кремниевого ядра $125 \mathrm{~nm}$ с осажденными на его поверхности НЧ золота $20 \mathrm{~nm}$ (сплошная линия - Si/Au) и спектры такого же количества НЧ золота (штриховая линия - $\mathrm{Au}$ ) и отдельной $\mathrm{HЧ} \mathrm{кремния} \mathrm{(пунктирная} \mathrm{линия}-\mathrm{Si}$ ) в воде.

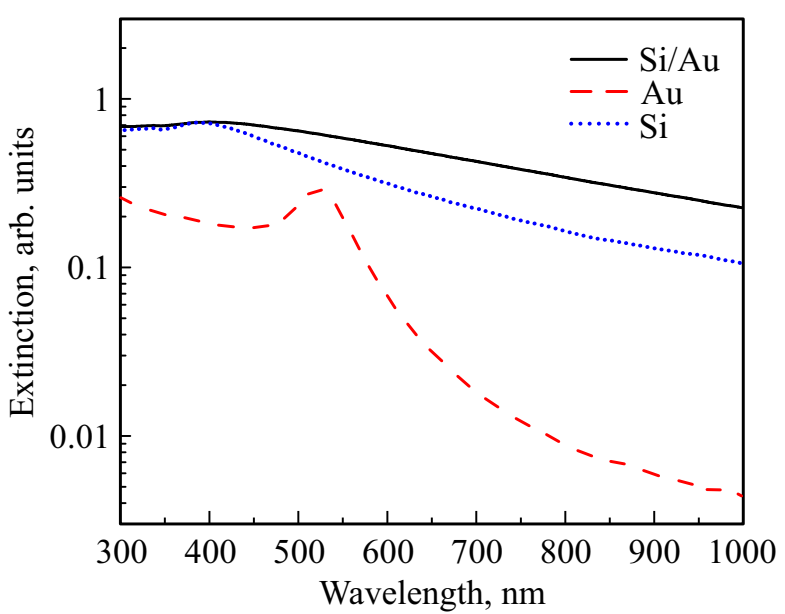

Рис. 4. Спектры экстинкции водных растворов НЧ кремния с золотом (сплошная линия - $\mathrm{Si} / \mathrm{Au}$ ), золота (штриховая линия - $\mathrm{Au})$ и кремния (пунктирная линия - $\mathrm{Si})$.

наложением рассеянных полей НЧ Аu из-за их близкого расположения друг к другу. Для нанокомпозитной частицы $\mathrm{Si} / \mathrm{Au}$ наблюдается также дополнительное усиление сечений поглощения и рассеяния в спектральной области наложения плазмонного резонанса золота и резонанса Ми кремниевой НЧ. При этом для НЧ $\mathrm{Si} / \mathrm{Au}$ и сечение поглощения, и сечение рассеяния в ближней ИК области увеличились более чем на порядок по сравнению со значениями для НЧ чистого $\mathrm{Si}$ и ансамбля НЧ $\mathrm{Au}$.

На рис. 4 представлены экспериментально измеренные спектры экстинкции водных растворов $\mathrm{HЧ} \mathrm{Si/Au} \mathrm{и}$ суспензий НЧ чистого $\mathrm{Si}$ и $\mathrm{Au}$. На спектрах последних отчетливо выражен пик на длине волны $520 \mathrm{~nm}$, соответствующий локализованному плазмону в золотых НЧ [2].
Для раствора кремниевых НЧ наблюдается обычное снижение степени поглощения в длинноволновой части спектра, в то время как для образца с НЧ $\mathrm{Si} / \mathrm{Au}$ виден рост коэффициента экстинкции в ближней ИК области более чем в 2 раза.

На рис. 5 представлены измеренные зависимости роста температуры для водных суспензий исходных НЧ $\mathrm{Si}$ (рис. 5,a) и композитных $\mathrm{HЧ} \mathrm{Si} / \mathrm{Au}$ (рис. 5,b) от времени лазерного облучения. Скорость нагрева водных суспензий НЧ $\mathrm{Si}$ при освещении зеленым $(532 \mathrm{~nm})$ и красным $(667 \mathrm{~nm})$ лазерами составляла $8 \mathrm{~K} / \mathrm{min}$ на начальном этапе, в то время как при облучении лазером с длиной волны $810 \mathrm{~nm}$ скорость нагрева была не более $1 \mathrm{~K} / \mathrm{min}$. Для НЧ $\mathrm{Si}$ с золотыми НЧ величина нагрева суспензий повысилась в соответствии с увеличением сечения поглощения частиц (рис. $3, a$ ). Скорость нагрева образца $\mathrm{Si} / \mathrm{Au}$ под воздействием лазеров с длинами волн 532 и $667 \mathrm{~nm}$ в начальный момент составила $12 \mathrm{~K} / \mathrm{min}$, при облучении светом с длиной волны $810 \mathrm{~nm}$ $7 \mathrm{~K} / \mathrm{min}$. Полученные данные подтверждают, что водные суспензии НЧ $\mathrm{Si} / \mathrm{Au}$ обладают значительно большей эффективностью поглощения света, особенно в ближней ИК области спектра, что хорошо соответствует как результатам расчетов (рис. 3), так и эксперимента (рис. 4).

\section{Заключение}

Таким образом, в работе были получены и исследованы композитные НЧ, представляющие собой НЧ кремния с размерами порядка $100 \mathrm{~nm}$ с осажденными на их поверхность НЧ золота меньших размеров. Экспериментально и теоретически обнаружено значительное увеличения поглощения и рассеяния в водных суспензиях композитных НЧ $\mathrm{Si} / \mathrm{Au}$ по сравнению с аналогичным количеством НЧ чистого кремния или золота. Получен- 

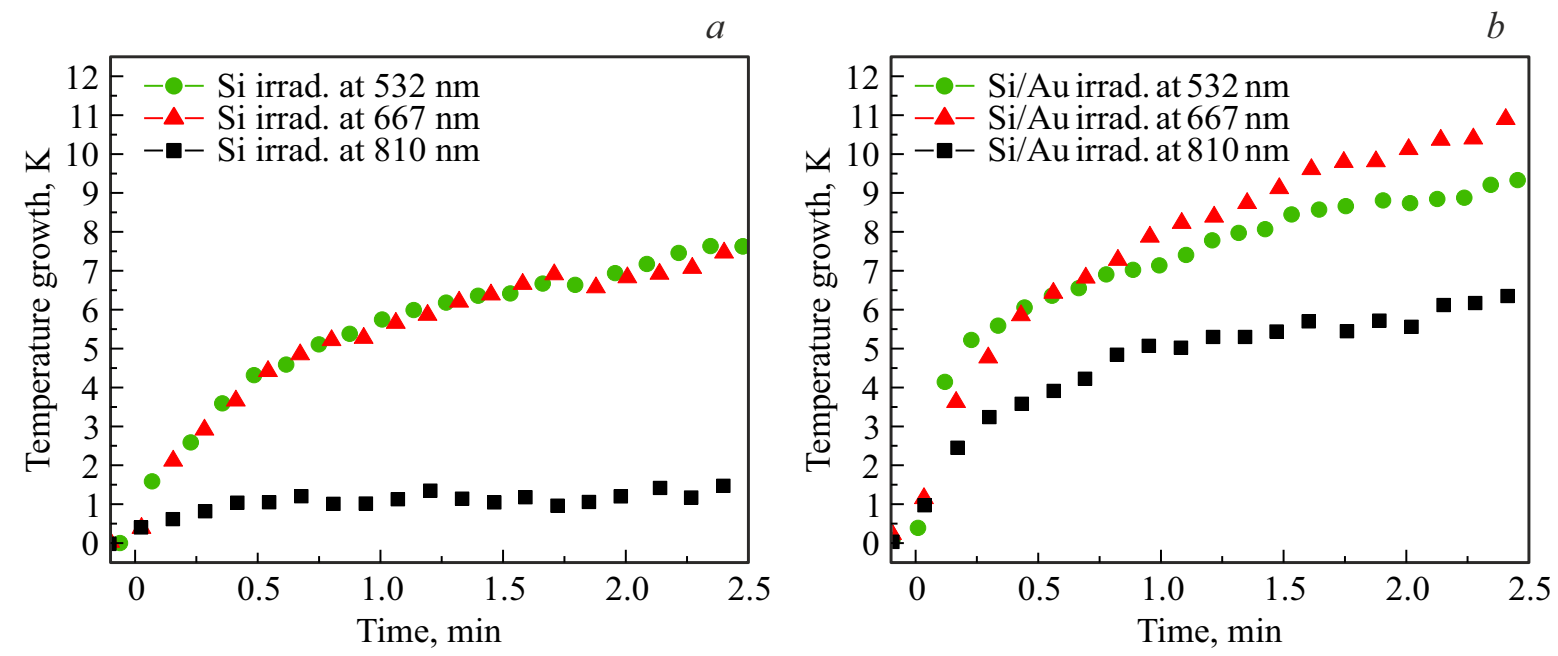

Pис. 5. (a) Зависимости от времени изменения температуры водных суспензий кремниевых НЧ и $(b)$ нанокомпозитных НЧ Si/Au при лазерном облучении с длиной волны $532 \mathrm{~nm}$ (зеленые кружки), $667 \mathrm{~nm}$ (красные треугольники) и $810 \mathrm{~nm}$ (черные квадраты). Начальная температура $20^{\circ} \mathrm{C}$, концентрации НЧ $1.8 \mathrm{~g} / 1$.

ные зависимости объясняются одновременным взаимодействием световой волны как с НЧ Si вблизи резонанса рассеяния Ми, так и с НЧ Аu в области локализованного плазмонного резонанса, что приводит к возникновению комбинированных резонансов, наблюдаемых в спектрах экстинкции водных суспензий $\mathrm{HЧ} \mathrm{Si} / \mathrm{Au}$. При этом, согласно выполненным расчетам, возникает резкое увеличение напряженности электрического поля вблизи НЧ $\mathrm{Au}$ при облучении светом с резонансной длиной волны. Рост сечения поглощения света проявляется также в более эффективном нагреве суспензии нанокомпозитных НЧ, особенно при лазерном облучении в ближней ИК области спектра. Полученные результаты перспективны для дальнейшего использования в фотогипертермии рака при облучении в окне прозрачности биотканей.

\section{Благодарности}

Авторы благодарны С.И. Кудряшову за полезные обсуждения, а также А.Е. Рупасову и С.Н. Шелыгиной за помощь в проведении экспериментов. Исследование выполнено при поддержке Междисциплинарной научно-образовательной школы Московского университета „Фотонные и квантовые технологии. Цифровая медицина“.

\section{Конфликт интересов}

Авторы заявляют, что у них нет конфликта интересов.

\section{Список литературы}

[1] А.В. Федоров, И.Д. Рухленко, А.Ф. Баранов, С.Ю. Кручинин. Оптические свойства полупроводниковых квантовых точек (Наука, СПб, 2011).
[2] A. Trügler. Optical Properties of Metallic Nanoparticles: Basic Principles and Simulation (Springer Ser. Mat. Sci., 2016).

[3] N. Sardana, V. Talalaev, F. Heyroth, G. Schmidt, Ch. Bohley, A. Sprafke, J. Schilling. Opt. Express, 24, 254-261 (2016).

[4] M. Mallory, E. Gogineni, G. Jones, L. Greerd, C. Simone. Crit. Rev. Oncol./Hematol., 97, 56-64 (2016).

[5] A.V. Kornilova, G.A. Kuralbayeva, A.V. Stavitskaya, M.V. Gorbachevskii, O.V. Karpukhina, I.V. Lysenko, V.V. Pryadun, A.A. Novikov, A.N. Vasiliev, V.Yu. Timoshenko. Appl. Surf. Sci., 566, 150671 (2021).

6] S. Amdouni et al. Mat. Sci. Semicond. Proc., 75, 206-213 (2018).

[7] A.V. Kabashin, M. Meunier. J. Appl. Phys., 94, 7941-7943 (2003). 